\title{
O controle da pobreza operado através do sistema penal
}

Fernanda Kilduff

Universidad Nacional de La Plata (UNLP), Argentina

\section{O controle da pobreza operado através do sistema penal}

Resumo: Com o objetivo de refletir sobre criminalização/penalização, este artigo analisa a virada neoconservadora em relação à política criminal, como mais uma expressão do conjunto de mudanças operadas no marco do capitalismo contemporâneo. Em um contexto caraterizado pelo retrocesso das políticas sociais, discute a expansão do sistema penal como estratégia privilegiada pelos Estados capitalistas para conter e administrar em forma criminalizadora as crescentes e cada vez mais complexas manifestações da "questão social" " atreladas a uma situação objetiva de desemprego maciço e estrutural. Para finalizar o debate, apresenta elementos tanto para refletir sobre a função histórica do direito penal burguês quanto para analisar seu papel fundamental na atual estratégia imperialista.

Palavras-chave: neoconservadorismo penal, política criminal, gestão da miséria, capitalismo contemporâneo.

\section{Poverty Control and the Penal System}

Abstract: To reflect on the criminalization and penalization of poverty, this article analyzes the neoconservative turn in criminal policy, as an expression of recent changes under contemporary capitalism. In a context characterized by a regression in social policies, the paper discusses the expansion of the penal system as a strategy used by capitalist States to contain and administer in a criminalizing form the growing and increasingly complex manifestations of the "social question" linked to an objective situation of massive and structural unemployment. To conclude the debate, it presents some elements to reflect on the historic function of bourgeois penal law and to analyze its fundamental role in current imperialist strategy.

Key words: penal neoconservativism, criminal policy, poverty management, contemporary capitalism. 


\section{Introdução}

O objetivo deste artigo é trazer reflexões sobre os processos de criminalização/penalização da pobreza no atual contexto de organização monopolista do capital. Assim, procura-se analisar a virada punitiva do Estado que se expressa claramente no acirramento das funções penais, repressivas e punitivas como forma de gestão da miséria, sendo os trabalhadores precarizados e/ou desempregados o alvo principal dessa política altamente letal.

No marco inicial, discute-se como, a partir dos anos 1970, uma destacada produção teórica e acadêmica norte-americana permitiu legitimar políticas criminais mais repressivas, que acabaram exportadas, sobretudo, para América Latina, como políticas exitosas de combate ao crime. Posteriormente, aborda-se um segundo eixo vinculado ao abandono ou declínio do ideal ressocializador como expressão dessa produção teórica.

Neste sentido é que se procura debater sobre as continuidades e rupturas das funções do cárcere, segundo as necessidades econômicas do capitalismo, destacando dois momentos históricos: o da sua origem e o da sua atualidade.

Após ter realizado uma aproximação às mudanças nas concepções teóricas, e seus rebatimentos nas políticas penitenciárias, segue-se trazendo ao debate a doutrina da "tolerância zero", a época do grande encarceramento, para finalizar com uma crítica à função histórica do direito penal na sociedade burguesa.

\section{A origem do neoconservadorismo penal: a experiência americana}

Wacquant (2002), coloca que, a destruição deliberada do (semi) ${ }^{2}$ Estado social e a hipertrofia súbita do Estado penal americano durante o último quarto do século 20 foram dois processos concomitantes e complementares.

A retração da rede de segurança social acontecida nos Estados Unidos, como também os graduais cortes orçamentários na assistência, na saúde pública, no ensino e na moradia, iniciados no começo dos anos 1970, devem ser compreendidos como parte da reação dos governos conservadores contra os movimentos progressistas americanos da década anterior ${ }^{3}$.

Dessa maneira, o incremento das funções penais e policias do Estado americano foram ocupando o lugar da política social, com forte deslocamento de recursos públicos de áreas sociais para a área de "segurança pública", para garantir a implementação de políticas basicamente repressivas e punitivas que envolveram tanto o setor penitenciário, como o judiciário e o policial.

Ao referir-se a esse fato, o penalista Anitua (2008, p. 765) diz que foi realizado:
[...] um desvio de recursos 'excedentes' do gasto em habitação, educação e demais cumprimentos de direitos sociais para reforçar o peso estatal em questões tradicionalmente reivindicadas pela direita, como os gastos militares, policiais e penitenciários, sob a bandeira de 'lei e ordem' ou 'segurança cidadã'.

Como no plano econômico, no campo da penalidade, as ideias conservadoras constituíram-se em um forte polo de atração ideológica. Os "teóricos" neoliberais americanos, atacaram os pressupostos do Estado fordista-keynesiano, responsabilizando-o não somente de não resolver a pobreza mas também de permitir a proliferação de condutas consideradas criminosas.

Por exemplo, destaca Anitua, para o conservador Jonh Iulio Jr., as políticas assistenciais destinadas às mães solteiras fomentavam o nascimento de filhos fora do casamento que careceriam dos cuidados necessários dentro de uma "família decente". E, aliás, o mesmo autor, extraía a conclusão que a próxima geração de jovens delinquentes seria especialmente violenta, predatória e perversa.

Outra característica central do pensamento neoconservador, e que teve importantes repercussões na legitimação de políticas criminais mais repressivas, é a simplificada e radical separação da sociedade em dois grupos bem definidos: por um lado os "bons" e pelo outro os "maus" os quais deveriam ser separados dos primeiros para não lhes causar danos. Nesta perspectiva, reapareceu com claridade a ideologia burguesa da defesa social, quer dizer, a que permite legitimar a aplicação do poder punitivo por parte do Estado com a finalidade de "proteger" a sociedade do crime. A esse respeito Wacquant (2007, p. 28) diz: "[...] a severidade penal é apresentada [...] por todas e por todos, como uma necessidade saudável, um reflexo vital do corpo social ameaçado pela gangrena da criminalidade." Dessa forma, reapareceram, na década de 1970, discursos e teorizações de traços marcada e abertamente racistas, evidenciando o desprezo pelas categorias populacionais consideradas, em termos de Wacquant (2007), "indesejáveis" ou em termos de Zigmunt Bauman (1999) "lixo humano". De acordo com Anitua, James Q. Wilson, converteu-se no criminólogo de cabeceira da direita punitiva norte-americana. Em 1975 ele escreveu Pensando sobre o delito que serviria de base de legitimação das políticas criminais que fariam disparar o número de pessoas presas nos Estados Unidos a partir de 1980 .

Outro livro, regido em 1985 pelo mesmo criminólogo conservador, em parceria com Richard Herrnstein (1930-1994), foi Delito e natureza humana, onde ambos os autores destacariam a importância de ver a criminalidade como um fato de opção individual, excluindo as suas explicações econômicas, políticas e sociais. Os criminólogos de direita 
associavam as causas da criminalidade ao hedonismo dos seres humanos, assim o ato delinquencial seria guiado pela busca de maior prazer, sendo a repressão severa a única alternativa possível.

Já em uma posição que não deixava dúvida da xenofobia e do racismo que norteavam as produções teóricas desses pensadores, Herrnstein também assinalava a importância da predisposição individual e suas raízes biológicas. Desta forma, a escolha do delito estaria determinada também por causas hereditárias.

Um elemento a mais que possibilita entender as modificações introduzidas pelo pensamento neoconservador na ideologia penal, e que terá repercussões diretas na política penal do último quartel do século 20, é o abandono da ideologia da "prevenção especial" ou ressocialização e, em contraposição, o enaltecimento da "prevenção geral", dissuasão ou intimidação. A esse respeito, Dornelles (2008, p. 35) coloca : "[...] as políticas penitenciárias ${ }^{4}$ passaram a abandonar a intenção de reabilitação e readaptação social. Se afasta a ideia de Estado terapêutico, orientado à recuperação integradora."

Em que pese historicamente a comprovação de que a pena não é preventiva de nada, os conservadores afirmavam que a dissuasão funcionava, mas se por alguma razão deixasse de fazê-lo, era porque os castigos não eram suficientes, sendo preciso aumentálos; e, de fato, foi o que aconteceu.

Segundo Anitua (2008, p. 797), por volta do final dos anos 1960 apareceram muitos trabalhos que defenderam essa concepção. Foi o caso do penalista Andenaes - que, citado por Anitua, afirmava: “[...] o homem racional teria medo das consequências desagradáveis e por isso a ameaça do castigo funcionaria para desmotivar o cometimento de atos delitivos."

Apesar de terem surgido pesquisas que tentavam comprovar que o efeito intimidatório funcionava na prevenção do delito, os penalistas conservadores, não estavam muito preocupados com os debates sobre as missões da prisão, sobre as causas e consequências do delito, nem pelos temas ligados à "reeducação" ou "reabilitação". Pelo contrário, suas discussões, estavam guiadas por princípios pragmáticos, centrando-se em como garantir uma eficiente administração penal.

Sobre isso, Wacquant (2007, p. 247) observa que

O abandono do ideal de reinserção (promovido pelas) críticas convergentes da direita e da esquerda nos anos 70 (foi substituído) por uma filosofia gerencial que evitava cuidadosamente enfrentar as causas e as consequências do encarceramento de massa [...]. A prisão serve, nessa ótica, para isolar e neutralizar categorias (populacionais consideradas) desviantes ou perigosas por meio de uma vigilância padronizada [...], cuja lógica evoca mais a pesquisa operacional ou a retirada dos 'dejetos sociais' do que o trabalho social.
Desta forma, enquanto os sujeitos se encontrassem encarcerados, eles estariam impossibilitados de cometer delitos, portanto, isso seria justificativa suficiente para considerar que a prisão funcionava. Em termos concretos, essa reatualização da prevenção significou que a privação da liberdade fosse explicitamente transformada em tortura. $\mathrm{O}$ que ainda melhor exemplifica a intenção explícita de infringir dor, é a proliferação de cárceres de máxima segurança, conhecidos como supermarx. Neste ponto, Wacquant (2007, p. 209) diz:

Alguns prisioneiros passam 22 horas sozinhos numa jaula de aço, sob supervisão eletrônica permanente, sem o menor contato humano durante anos. [...] a prisão é o lugar de 'uma monotonia mortificante', continuamente mantida pela inatividade forçada e pela superpopulação [...].

Bauman (1999, p. 121), exemplificando essa situação, coloca como na prisão Pelican Bay ${ }^{5}$ levou-se quase à perfeição a técnica da "imobilização": "[...] o que os internos [...] fazem em sua celas solitárias não importa. O que importa é que fiquem ali [...] (ela) foi planejada como fábrica de exclusão de pessoas habituadas a sua condição de excluídas 6 ."

Também, pode-se ver como os penalistas conservadores, na mesma linha que orientou a privatização, centralização e focalização das políticas sociais ${ }^{7}$, centraram as críticas nas políticas penais tendentes à ressocialização; consideradas, conforme Anitua, como um enorme gasto desnecessário a ser dispendido pelas pessoas "honradas". Portanto, o acesso a determinados "benefícios" dentro da prisão seria considerado privilégio e não direito 8 , "eles", "os outros", "os maus", não mereceriam mais que o desprezo e o ódio da sociedade.

\section{As rupturas e as continuidades na prisão, segundo as necessidades econômicas do momento histórico}

Até aqui, observamos que esta ideologia segregativa e punitiva aparta, a ideologia da ressocialização, que, até a década de 1970, incidiu de forma mais decisiva sobre as políticas penais implementadas.

Uma chave para a compreensão do porquê da crise da tradicional ideologia legitimadora da pena (reeducação) pode ser encontrada em Rusche e Kirchheimer (2008), penalistas da Escola de Frankfurt. Ambos os autores destacam que as teorias da pena não chegam a explicar a introdução das formas específicas de castigo no conjunto da dinâmica social, sendo necessário relacionar os sistemas punitivos concretos às exigências próprias do modo 
de produção capitalista. Eles destacam como, na sociedade capitalista, o sistema penitenciário depende, sobretudo, do desenvolvimento do mercado de trabalho: "La magnitud de la población carcelaria y su empleo como mano de obra dependen del aumento o de la disminución de la fuerza de trabajo disponible en el mercado y de su utilización" (RUSCHE; KIRCHHEIMER, 2004 apud BARATTA, 2004, p. 203).

No início, o cárcere, esteve ligado ao surgimento da sociedade capitalista, tendo por finalidade transformar massas de camponeses em modernos operários das fábricas, sendo essa a real e verdadeira função reeducativa. Neste ponto, Dornelles (2008, p. 36) agrega:

[...] as instituições totais de segregação (prisão, manicômio, hospital, casas de correção, orfanatos, escolas etc.) cumpriam o papel disciplinar adestrador para uma permanente capacitação de potenciais trabalhadores úteis ao sistema produtivo.

Apesar das concepções de "reeducação" e "reabilitação" serem mitos burguêses porque, como está mais que comprovado, o aprisionamento exerce efeitos contrários a uma possível inclusão positiva do sujeito à sociedade, elas têm sentido na origem do capitalismo, quando a nascente burguesia precisou inserir o proletariado no monótono, rotineiro e mecânico ritmo do trabalho industrial moderno.

Com efeito, se os operários não se submetiam à exploração, se não conseguiam vender sua força de trabalho - fosse por razões voluntárias ou involuntárias - eles encontrariam no aprisionamento um local onde a exploração era o destino certo, e, aliás, sem o recebimento de um salário. Portanto, para os capitalistas, o aproveitamento dos internos no trabalho era ainda mais lucrativo.

Voltando à época atual, para entender o abandono ou o declínio do ideal ressocializador - que nos permite pensar nas funções históricas e atuais do cárcere -, é preciso considerar um elemento estrutural característico da fase atual do desenvolvimento capitalista.

A marca de nossa época é a tendência ao incremento da sobrepopulação relativa pelo aumento do desemprego e subemprego, como também da intensificação da exploração da força de trabalho. Esta situação revela uma mudança do cárcere a respeito da sua origem:

[...] la diferencia es (que ele) [...] fue central para la producción (da classe operária) [...], la cárcel ya no tiene la función real de reeducación y de disciplina que había asumido en su origen. Esa función educativa se reduce hoy a pura ideología (BARATTA, 2004, p. 204-205).
O abandono explícito dessa função reeducativa mesmo sendo pura ideologia - que se revela no pensamento penal contemporâneo coincide, conforme Baratta, com o mesmo momento em que a estratégia conservadora deixa cair o mito da plena ocupação tão característico da fase capitalista anterior.

Pela observação de Bauman (1999, p. 120):

[...] o confinamento não é nem escola para o emprego, nem o método compulsório de aumentar as fileiras de força de trabalho produtiva quando falham os métodos ‘voluntários' [...] para levar à orbita industrial aquelas categorias rebeldes e relutantes de 'homens livres'. Nas atuais circunstâncias o confinamento é antes uma alternativa ao emprego, uma maneira de [...] neutralizar uma parcela considerável da população que não é necessária e para a qual não há emprego 9 'ao qual se integrar'.

Embora essa diferença esteja certa, também existe um elemento que marca uma importante continuidade em sua função social, porque continuamos sob o comando do modo de produção capitalista. Esse elemento de permanência vincula-se à sempre presente preocupação burguesa em controlar e castigar a classe trabalhadora, o que se constituiu em uma ameaça - real ou potencial - para o regime de propriedade privada.

Em definitivo, no marco da sociedade capitalista, será que podemos afirmar que a política criminal implementada pelos Estados esteve sempre politicamente orientada a ensinar aos não proprietários a aceitar resignadamente essa condição?

\section{0 neoconservadorismo penal em ação: a doutrina da tolerância zero e a justificativa da eliminação do "inimigo"}

A pesquisa e divulgação ideológica da penalidade neoconservadora foram realizadas, sobretudo, pelo Manhattam Institute e a Heritage Foudation, que, conforme Wacquant (1999), iniciaram nos Estados Unidos, a campanha de penalização da pobreza. Ambos os organismos foram os responsáveis pela promoção do que se conheceu como a "teoria" das "janelas quebradas" 10 que sustentava enfaticamente a necessidade de punir os pequenos delitos para prevenir delitos mais graves.

Segundo Dornelles (2008), a teoria das broken windows serviu de base criminológica para a reorganização da atividade policial, que foi conhecida como "tolerância zero" ${ }^{11 "}$. Essa política traduziu-se em uma elevação massiva do orçamento policial (com aumento do número de efetivos e equipamentos policiais) e em maiores poderes e liberdades ao agir policial. 
Wacquant (1999, p. 28-29), analisar suas consequências:

$$
\begin{aligned}
& {[\ldots] \text { tolerancia cero }[\ldots] \text { significó perseguir }} \\
& \text { agresivamente la pequeña delincuencia, expulsar a } \\
& \text { los mendigos y a los sin techo de las calles [...] se } \\
& \text { acabó puniendo severamente infracciones meno- } \\
& \text { res }[\ldots] \text { castigou-se a pequeños revendedores de } \\
& \text { droga, prostitutas, mendigos, vagabundos, auto- } \\
& \text { res de grafitis. En definitiva al subproletariado que } \\
& \text { representa una amenaza. A él apunta priorita- } \\
& \text { riamente a política de tolerancia cero. }
\end{aligned}
$$

Aliás, essa concepção foi exportada como uma exitosa política de luta contra a "insegurança". Do mesmo modo que as receitas ortodoxas no plano econômico, ela foi assumida pelos governos neoliberais da Europa e da América Latina.

Integrando essa propaganda ideológica, os conservadores atribuíram às medidas implementadas 0 fato de ter reduzido a criminalidade: "A ideia de "tolerância zero' passou a ser a panaceia, o remédio universal para todos os males da delinquência, das transgressões sociais e da desordem urbana" (DORNELLES, 2008, p. 64).

Young (2002) aponta a falsidade das afirmações dos defensores desta política. Para o autor, embora a criminalidade em Nova Iorque tenha diminuído no período 1993-1996, isso não se deveu às "inovadoras" práticas policiais: "[...] o declínio da criminalidade ocorreu em 17 das 25 maiores cidades dos Estados Unidos (mas aconteceu) onde não houve nenhuma mudança de policiamento e mesmo em alguns lugares em que houve uma redução do número de policiais [...]" (YOUNG, 2002, p. 184).

Para Wacquant (2002), o que mudou radicalmente não foi a criminalidade - cujos indicadores mostravam que tendia a manter-se ou a diminuir ${ }^{12}$ - mas a atitude dos poderes públicos com relação aos pobres, considerados o centro irradiador do crime.

Como vemos então, existiu uma mistificação e uma manipulação informativa sobre os êxitos da chamada política de "tolerância zero" com relação ao controle da criminalidade. Outro elemento característico desta política, foi a retórica da guerra (luta contra o crime, combate às gangues etc.), relacionada às mudanças no plano internacional, que os governos conservadores dos Estados Unidos introduziram em matéria de narcóticos ${ }^{13}$. A esse respeito Batista (2003, p. 84, grifos da autora) destaca: "No início dos anos 70 aparecem as primeiras campanhas de 'lei e ordem' tratando a droga como 'inimigo interno', formando-se um discurso político para que a droga fosse transformada em uma ameaça à ordem."

A política imperialista norte-americana, na sua necessidade de encontrar novos perigos que justificassem a intervenção militar, encontrou na "guerra contra as drogas" os motivos para lançar uma nova campanha de repressão, uma vez que a ameaça do comunismo perdera sua força, particularmente na América Latina.

Para Batista (2003, p. 12) esse fato retrata que "[...] os Estados Unidos, a partir dos anos 80, utilizam o 'combate às drogas' como eixo central da política americana no continente [...] As drogas passam a ser o eixo das políticas de segurança nacional nos países atrelados a Washington."

Nessa perspectiva, Zaffaroni (2007), ao assinalar a identidade do poder bélico com o poder punitivo na busca desesperada ao inimigo, destaca o papel central da ofensiva da doutrina Bush após o 11 de setembro de $2001^{14}$ e a sua declaração de guerra ao terrorismo islâmico; para preencher, como foi colocado, o vazio deixado pela implosão soviética.

Young (2002) coloca o extraordinário paralelo que existe entre a guerra e a criminalidade, quanto à mobilização da agressividade. Destaca que, para criar um "bom inimigo", temos que ser capazes de nos convencer que eles são as causas de todos os nossos problemas, facultando dirigir a animosidade contra eles. Devemos acreditar que eles também seriam, intrinsecamente, diferentes de nós (eles sintetizariam a corrupção, o mal, e a degradação), o que habilitaria e legitimaria ao Estado o uso da violência.

Conforme Zaffaroni (2007, p.18), o conceito mesmo de inimigo introduz a dinâmica da guerra no Estado de direito:

A essência do tratamento diferenciado que se atribui ao inimigo consiste em que o direito lhe nega sua condição de pessoa. Ele é considerado sob o aspecto de ente daninho ou perigoso [...] estabelece-se a distinção entre cidadãos (pessoas) e inimigos (não pessoas), faz-se referência a certos seres humanos que são privados de certos direitos individuais.

Neste passo, na lógica da guerra, suprimem-se os direitos constitucionais da cidadania e o inimigo é simplesmente um alvo que se deverá destruir.

Essa lógica belicista foi introjetada nas políticas de "segurança" pública, implementadas pelos governos neoconservadores; nas quais prevalece a lógica do confronto e a repressão direta. A esse respeito, Dornelles coloca (2008, p. 181): "Uma lógica que identifica mecanicamente as classes subalternas como agente do crime, como classes perigosas e os bairros e favelas como 'áreas de risco' [...] levando a aplicação de políticas que [...] atingem o conjunto da população mais pobre."

\section{O grande encarceramento}

A hiperinflação carcerária deve ser entendida como uma das consequências mais reveladoras das políticas ultrarrepressivas, implementadas nas últimas décadas. 
Wacquant (2007) aborda a experiência prisional dos Estados Unidos por ser precisamente o país líder mundial do encarceramento em massa após a década de 1970. No intuito de mostrar o clima desfavorável a uma política de "lei e ordem", Zaffaroni (2007) coloca como a pena de morte nos EUA parecia chegar ao fim quando, em 1972, a Corte Suprema declarava a sua inconstitucionalidade e os índices de aprisionamento se mantinham estáveis desde o século 19.

Essa tendência foi drasticamente revertida e a prisão voltou a ter um lugar de destaque, apresentando-se como um meio simples e direto de restaurar a ordem. A demografia carcerária, após 1973, começou a aumentar vertiginosamente e a pretensa "guerra ao crime" fez dobrar a população carcerária do país em dez anos, e quadruplicá-la em vinte.

Enquanto, em 1975, os detentos não chegavam a 380 mil, em 1980, o número de presos era de 500 mil. Em 1990, atingia a mais de 1 milhão, chegando a quase 2 milhões em 2000.

Wacquant (2007), para refutar o discurso político da direita e da mídia, que justifica o aumento do aprisionamento por causa do aumento da criminalidade violenta, explica essa inflação permanente e acelerada pelo incremento de medidas e de leis definidamente mais punitivas.

Comparado com a política penal anterior - do segundo pós-guerra até os anos 1970 -, a hiperinflação carcerária deu-se pela extensão do recurso do aprisionamento para uma série de delitos que até então não levavam à pena de prisão; também pelo aumento do tempo de duração das penas para delitos sem gravidade e pelo incremento dos castigos para os crimes violentos, com o cumprimento de penas em regimes fechados. A partir do período histórico destacado e a pretensa "guerra contra a droga", o encarceramento se aplica com enorme frequência e severidade aos pequenos consumidores e vendedores de entorpecentes, que são jogados na prisão aos milhares.

Garland (1999) indica como a mídia e os partidários das políticas tipo "lei e ordem" invocam - quando acontece um crime violento - o dano causado à vítima, para criar um clima de pânico generalizado, e lograr o apoio social para a aprovação de leis penais mais severas.

Conforme Anitua (2008), essas mudanças nas legislações, em termos de endurecimento penal, devem ser entendidas como produto de um "populismo punitivo", que refere a atitude dos políticos com as vistas voltadas para a velha ferramenta punitiva que oferecem a uma sociedade assustada, em uma clara demonstração de que "estão fazendo alguma coisa" pela segurança pública. No marco desta perspectiva, a extensão das sentenças, por exemplo, não dependeria tanto da natureza da ofensa senão da cons- trução de "perfis de risco", que, seria quase suficiente para encarcerar alguém.

A esse respeito, referindo-se à lógica da penalogia neoliberal, De Giorgi (2006, p. 97), diz: “As novas estratégias penais se caracterizam cada vez mais como dispositivos de gestão de risco e de repressão preventiva das populações consideradas portadoras desse risco [...]". Dessa forma, o cárcere funciona como mero depósito de grupos populacionais considerados "naturalmente" perigosos e de risco para os quais não resta outro remédio senão aplicar e reforçar técnicas de controle cada vez mais capilares e totalizadoras.

Cabe colocar como essa concepção de "risco" e "periculosidade" se fez, nos últimos anos, significativamente extensiva a grande parte dos segmentos mais deteriorados da classe trabalhadora. Foi neste cenário, que o cárcere voltou a ter centralidade como um instrumento privilegiado de gestão e penalização da miséria.

Wacquant (2007) explica como o excessivo custo econômico do aprisionamento de massa serviu de base de argumentação para que o governo norteamericano apelasse ao setor privado - orientado pela ideologia da mercantilização. Ao buscar descomprimir o caos financeiro que essa política estava causando, ao mesmo tempo oferecia um novo nicho lucrativo a esse setor ${ }^{15}$.

Nesta conjuntura, diversas empresas privadas entraram no mercado da construção e gestão de prisões, embora elas não tivessem sido as únicas a lucrar com a hiperinflação carcerária. Também setores envolvidos em garantir determinados bens e serviços, tais como alimentação, telefonia, transporte, tecnologias de identificação e vigilância, atenção médica, entre outros, vieram a ser grandemente beneficiados.

Como um aspecto de novidade nas formas de penalização da pobreza característica do capitalismo contemporâneo, os "indesejáveis", os "párias" urbanos, além de serem vítimas do desemprego em massa, do trabalho precário, do recuo das políticas sociais e do aumento de medidas mais punitivas, foram submetidos à lógica perversa do encarceramento privado, para desta maneira contribuírem com a acumulação de capital.

\section{A função histórica e crítica do direito penal burguês}

De Giorgi (2006) coloca que o fato da população carcerária ser constituída por pobres, desempregados e subempregados não é nenhuma novidade; ao contrário, trata-se de uma constante histórica que os acontecimentos norte-americanos evidenciaram com maior intensidade. Para o mesmo autor, o que mudou, e de modo significativo, foi a relação entre instituições sociais e penais na gestão da pobreza. 
Ao destacar a virada punitiva, Motta (2005, p. 32) assinala como, cada vez mais, ser pobre é encarado como um crime: " $[\ldots]$ os pobres, ao invés de fazerem jus aos cuidados de assistência, merecem ódios e condenação."

No marco da atual estratégia imperialista de controle da miséria, "combater a pobreza" significa carta branca às forças repressivas estatais para uma perseguição cada vez mais agressiva aos considerados criminosos, perigosos e indesejáveis, que chegam a ser até tratados de "lixo humano" que deve ser exterminado.

É precisamente no marco da ofensiva neoliberal do capital sobre o trabalho - onde se opera verdadeira desvalorização e destruição de ativos, e entre eles a força de trabalho - que pode ser compreendido, em termos de Zaffaroni (2007), o número crescente de mortes efetuadas por grupos policiais e parapoliciais de extermínio em várias regiões; as mortes violentas em motins carcerários; a violência exercida contra presos nas prisões; as doenças não tratadas também nos cárceres, e mortes e mais mortes em tantas outras situações.

Como foi observado, o poder punitivo do Estado não atinge - nem nunca atingiu - a toda a sociedade indiscriminadamente. Pelo contrário, a violência sempre foi exercida sobre os setores da classe trabalhadora (sejam eles camponeses ou operários urbanos) que - real ou potencialmente - ameaçam o regime capitalista, caracterizado pela propriedade privada dos meios de produção.

Como afirma Pavarini (2003, p. 32) - em uma clara perspectiva marxiana -, a brutal legislação penal já nos séculos 16 e 17 estava orientada às necessidades do nascente capitalismo, expulsando violentamente, por exemplo, os camponeses das terras para obrigá-los a converter-se em proletários industriais:

[...] cuando los niveles cuantitativos de la fuerza de trabajo expulsada del campo fueron superiores a las posibilidades efectivas de su empleo [...] la única posibilidad de resolver la cuestión del orden público fue la eliminación física para muchos y la política del terror para los demás.

Tanto na origem dessa formação econômico-social como até hoje, o Estado burguês, amparado na utilização do direito penal, como também em outro conjunto de instituições, visa garantir a conservação e a reprodução das relações sociais capitalistas. Neste processo de gestão e eliminação constante dos "sobrantes", como diz Wolff (2005), as políticas criminais têm então um papel crucial, pois validam a seleção de quem deve ser criminalizado através do sistema penal ${ }^{16}$. Assim essa seleção, que segue um histórico critério classista, orienta-se e legitima-se socialmente pela construção de estere- ótipos que fixam características negativas à população empobrecida.

Batista (2003, p. 23), ao analisar o processo de criminalização por drogas no Rio de Janeiro, destaca a seletividade de classe na aplicação da lei penal segundo sejam eles jovens ricos ou pobres. A esse respeito coloca: "Aos jovens consumidores das classes média e alta se aplica o paradigma médico, enquanto aos jovens moradores de favela e bairros pobres se aplica o paradigma criminal."

A partir do até aqui analisado, fica evidenciado o mito burguês da igualdade de todos os cidadãos ante a lei em geral e ante a lei penal em particular.

A esta situação Marx brinda com uma importante análise na Crítica do programa de Gotha (1985) quando discute o direito burguês como direito desigual. $\mathrm{O}$ autor destaca a relação desigual existente na forma jurídica do contrato "entre iguais", denunciando como essa igualdade formal encobre a desigualdade substancial existente entre proletários - obrigados a vender sua força de trabalho para sobreviver a partir da expropriação dos meios de vida por parte dos capitalistas - e os burgueses.

Apesar do conceito liberal de igualdade ante a lei estar fortemente enraizado na sociedade, a profunda seletividade que percorre as diferenças desde o acesso, passando pela aplicação e chegando à instância da execução penal, permite-nos desmistificar a ideia burguesa de serem "todos iguais" perante a lei. Para Baratta (2004, p. 173):

[...] no solo las normas del derecho penal se forman y se aplican selectivamente, reflejando las relaciones de desigualdad existentes, sino que el derecho penal ejerce una función activa de reproducción y producción, respecto de esas relaciones de desigualdad.

Além do mais, o direito penal - como discurso justificador da intervenção do sistema penal - longe de proteger os interesses gerais da sociedade - outro mito burguês - protege os interesses dos grandes proprietários do capital.

Enquanto os pequenos delitos são efetivamente perseguidos e penalizados, os delitos denominados de "colarinho branco" gozam de tremenda impunidade. Ao mesmo tempo em que se criminalizam delitos comuns, os delitos que provocam grandes danos sociais e ecológicos, cometidos pelas grandes corporações econômicas, por sua vez, gozam de uma quase total - quando não total - imunidade legal.

A manipulação ideológica orquestrada, principalmente pela mídia, faz com que o alarme social seja inversamente proporcional ao dano social causado. Em assassinato, ou em roubo individual, que atinge a umas poucas vítimas, a sociedade quer punir implacavelmente seu autor, enquanto quase ninguém rea- 
ge contra a criminalidade que danifica as maiorias, seja ela cometida pelas corporações financeiras, pelos bancos que lavam dinheiro do tráfico de drogas, ou pelas indústrias de cigarros ou bebidas alcoólicas, entre tantas outras.

É preciso denunciar o caráter ideológico do direito penal que, além de não ser igual para todos nem defender os interesses de todos, tampouco - como é enfatizado pelo abolicionismoresolve conflitos e problemas de grande envergadura como o da segurança pública ou o do aumento da criminalidade. Pelo contrário, longe disso, acaba agravando-os.

Assim, por detrás dessas soluções ilusórias que produzem mais mortes e destruição social, esconde-se a verdadeira essência do direito penal burguês, que, sobre a base de um corpo doutrinário de normas, legitima como necessária a intervenção de tipo repressiva sobre tudo aquilo considerado como uma ameaça e um estorvo ao modo de produção capitalista.

Embora isto tenha uma continuidade histórica, a fase neoliberal do capitalismo revela a expansão do sistema penal como estratégia privilegiada de controle e gestão da pobreza, aprofundada principalmente por uma situação de desemprego maciço e estrutural.

Como confirma Menegat (2006, p. 41), ao recuperar os aportes de Baratta: "[...] quanto mais desigual é uma sociedade tanto mais ela tem necessidade de um sistema de controle social [...] de tipo repressivo, como é o realizado através do sistema penal do direito burguês."

\section{Considerações finais}

A organização da punição - como sustenta Menegat (2006) - é parte do controle que acompanha a história da humanidade desde os tempos mais remotos. No entanto, a forma em que ela é posta nas mais diferentes sociedades, varia segundo as suas necessidades sociais. Harvey (2005), ao caracterizar o capitalismo na fase contemporânea, coloca que o capital, na procura por se valorizar - à tradicional forma de reprodução expandida via exploração da força de trabalho -, agrega processos de acumulação por despossessão. Nesse sentido, abre de forma violenta novos mercados, visando uma colocação lucrativa do capital excedente, controlando militarmente e desbastando os territórios ricos em recursos naturais, conta- minando o meio ambiente, avançando sobre os ativos públicos estatais, cancelando direitos trabalhistas e destruindo a força de trabalho que lhe é supérflua para suas necessidades de incorporação dentro dos processos produtivos; chegando até ameaçar a própria sobrevivência da vida humana no planeta.

Desta forma, na atual organização monopolista do capital, processos de espoliação e mecanismos de destruição e barbárie ${ }^{17}$ são exacerbados. Com o olhar para a atual estratégia imperialista, pode-se compreender as mudanças nas políticas criminais, que - operacionalizadas através dos sistemas penais - provocam um verdadeiro genocídio em andamento.

As reorientações da política criminal na contemporaneidade procuram, de um lado, garantir a gestão da miséria provocada por desemprego maciço e estrutural, e, de outro, visam constituir-se em mercados lucrativos para o capital.

Interesses políticos e econômicos estão absolutamente imbricados no conjunto de mudanças que envolvem desde sanções de leis mais punitivas, até uma agressiva tarefa policial. Essa situação se complementa com o sistema prisional transformado, cada vez mais, num mero depósito de seres humanos, os quais, nesta sociedade, não merecem outra coisa senão ódio e desprezo. E, convertidos em inimigos públicos número um, tornam-se os bodes expiatórios responsáveis por todos os nossos males.

Esta letal política criminal, profundamente seletiva e classista e com traços marcadamente racistas e xenófobos, legitima o agir dos Estados que - de forma mistificada - aparecem como protetores da sociedade contra o "crime" e, em nome da segurança pública, não fazem outra coisa que criminalizar, de forma cada vez mais ostensiva, a pobreza e a miséria, derivadas do desemprego e/ou do emprego precário, cujas dimensões atuais são inéditas.

\section{Referências}

ANITUA, G. Histórias dos pensamentos criminológicos. Rio de Janeiro: Revan, 2008.

BARATTA, A. Criminología crítica y crítica del Derecho Penal. Buenos Aires: Siglo XXI, 2004.

BATISTA, V. M. de S. W. Difíceis ganhos fáceis: drogas e juventude pobre no Rio do Janeiro. Rio de Janeiro: Objetiva, 2003. 
BAUMAN, Z. Globalização: as consequências humanas. Rio de Janeiro: Zahar, 1999.

DE GIORGI, A. A miséria governada através do sistema penal. Rio de Janeiro: Revan, 2006. (Coleção Pensamento Criminológico).

DORNELLES, J. R. Conflito e segurança. Rio de Janeiro: Lumen Juris, 2008.

GARLAND, D. As contradições da 'sociedade punitiva'. Revista de Sociologia e Política, Curitiba, n. 13, p. 59-80, nov. 1999.

HARVEY, D. O novo imperialismo. São Paulo: Loyola, 2005.

IAMAMOTO, M. V. Servicio Social y division del trabajo. São Paulo: Cortez, 1997.

MARX, K.; ENGELS, F. Crítica do Programa de Gotha. Moscovo: Progresso, 1985. (Obras Escolhidas, tomo III)

MENEGAT, M. O olho da barbárie. São Paulo: Expressão Popular, 2006.

MOTTA, A. P. As garantias processuais e o direito penal juvenil. Porto Alegre: Livraria do Advogado, 2005.

PAVARINI, M. Control y dominación. Buenos Aires: Siglo XXI, 2003.

RUSCHE, G.; KIRCHHEIMER, O. Punição e estrutura social. Rio de Janeiro: Revan, 2008. (Coleção Pensamento Criminológico).

WACQUANT, L. Las cárceles de la miseria. Buenos Aires: Manantial, 1999.

A ascensão do Estado penal nos EUA. Discursos sediciosos - Crime, direito e sociedade. Rio de Janeiro: Revan, n. 11, p. 15-22, jan./jun. 2002.

Punir os pobres. A nova gestão da miséria nos Estados Unidos. Rio de Janeiro: Revan, 2007.

WOLFF, M. P. Antologia de vidas e histórias na prisão. Rio de Janeiro: Lumen Juris, 2005.

YOUNG, J. A sociedade excludente. Rio de Janeiro: Revan, 2002.

ZAFFARONI, R. E. O inimigo no Direito Penal. Rio de Janeiro: Revan, 2007.

\section{Notas}

1 Segundo Iamamoto (1997, p. 21), o conceito refere-se ao "conjunto de problemas políticos, sociais e econômicos que o surgimento da classe operária impõe na constituição da sociedade capitalista. Assim estaria relacionado fundamentalmente ao conflito entre o capital e o trabalho.'

2 Waqcuant (2007) demonstra que nos Estados Unidos o Estado social sempre foi extremamente subdesenvolvido, comparando-se com os países da Europa Ocidental.

3 A década de 1960 caraterizou-se por diversas revoltas encabeçadas pelos movimentos contra a Guerra de Vietnã, pela afirmação dos direitos civis dos negros, pelo reconhecimento dos direitos das minorias gays, entre outros.

4 Concebe-se a política penitenciária integrando a política penal, e a essa última, conforme Baratta (2004), como uma resposta à questão criminal circunscrita no âmbito de exercício da função punitiva do Estado (lei penal e a sua aplicação, execução da pena e as medidas de segurança).

5 Prisão estatal de máxima segurança situada na Califórnia, Estados Unidos.

6 Nos termos que se pensa aqui a exclusão é a expulsão sistemática de pessoas do acesso: ao mercado formal de trabalho, à saúde e educação, à moradia digna, ao lazer e aos bens estéticos; ali, ao contrário, elas estão bem incluídas em um plano estatal de repressão e extermínio.

7 Nesta conjuntura, as políticas sociais foram substancialmente modificadas em seus formatos, em seus conteúdos e, principalmente, em seus fundamentos, devido aos conservadores rejeitarem os conceitos de direitos sociais e de obrigação da sociedade em garantir bens e serviços por meio da ação estatal; eles se opõem à universalidade, igualdade e gratuidade dos mesmos.

8 Wacquant (2007, p. 298) exemplifica como essa concepção se traduziu nas prisões norte-americanas no aprofundamento da deterioração do alojamento, da higiene, dos cuidados médicos, do acesso à visita, à recreação e ao lazer. O mesmo autor destaca o cancelamento de tratamentos terapêuticos por adições a substâncias psico-aditivas como também a supressão de programas de formação laboral.

9 A noção de falta de emprego, colocada por Bauman, não é dirigida a sustentar a tese do fim do trabalho. Apesar de as inovações tecnológicas, introduzidas no mundo do trabalho e das finanças nos últimos anos, aprofundarem a tendência inerente ao modo de produção capitalista de prescindir do trabalho vivo.

10 O livro Janelas quebradas: a polícia e a sociedade nos bairros, publicado em 1981 por James Q. Wilson e George 
Kelling, explicava o uso dessa metáfora:“[...] se uma janela de um edifício está quebrada e se ela não é consertada, as demais janelas em pouco tempo estarão quebradas também, porque uma janela sem conserto é sinal que ninguém se preocupa com ela e, portanto, quebrar mais janelas não teria custo algum" (apudANITUA, 2008, p. 783).

11 Implementada a partir de 1993, sob o comando de William Wratton, chefe da polícia de Nova Iorque na gestão do prefeito Rudolph Giuliani.

12 "A quantidade de assassinatos havia caído pela metade entre 1990 e 1994, como também os crimes contra o patrimônio caíram 25\% no mesmo período [...]" (WACQUANT, 2002 apudDORNELLES, 2008,p.63).

13 A partir dos anos 1970, com Nixon e, sobretudo, nos anos 1980, com Reagan.

14 Zaffaroni (2007) destaca que, após o atentado, o poder bélico tomou emprestada a noção de "prevenção" do discurso penal e pretendeu apresentar a guerra contra o Iraque como "preventiva". Depois de 2001, efetivamente, desencadeiase uma série de guerras "preventivo-repressivas", nas quais os Estados Unidos atacam unilateralmente por "periculosidade presumida".

15 A campanha de privatização foi lançada pelo governo Reagan e encorajada pelo thin thanks neoconservadores e pelas grandes firmas que operavam em Wall Street.

16 "Por 'sistema penal' entendemos [...] a soma dos exercícios de poder de todas as agências (policial, judiciária e penitenciária)"(ZAFFARONI, 2001,p. 144).

17 Significa que o capital se reproduz, embora com custos sociais cada vez mais elevados.

\section{Fernanda Kilduff}

ferkilduff@yahoo.com.ar

Docente da Facultad de Trabajo Social (FTS) da Universidad Nacional de La Plata (UNLP)

Doutoranda do Programa de Pós-Graduação da Escola de Serviço Social da Universidade Federal do Rio de Janeiro (UFRJ), Bolsista do CNPq (20072009)

Orientador: Prof. Dr. Carlos Eduardo Montaño

\section{FTS - UNLP}

Calle 9 esq. 63, La Plata

Buenos Aires - Argentina

C.D. 1900 